\title{
A (RE) CONSTRUÇÃO DA GEOMORFOLOGIA SEMIÁRIDA A PARTIR DO CONHECIMENTO TRADICIONAL: A Etnogeomorfologia Sertaneja
}

\author{
(RE) CONSTRUCTING SEMII-ARID GEOMORPHOLOGY \\ FROM TRADITIONAL KNOWLEDGE: \\ Brazilian Backlands Etnogeomorphology
}

Simone Cardoso Ribeiro ${ }^{1}$ simonecribeiro@oi.com.br

\begin{abstract}
This article aims to discuss the northeastern semiarid geomorphology from the ethno scientific knowledge, aiming at understanding how the main modifying agents of the backwoods space understand the geomorphic processes, how they use this knowledge to manage the environment in which Live and if, and how, they use this knowledge for some type of relief taxonomy. We can conclude that the rural producers of the backwoods have vast knowledge about relief sculpturing processes, dominating their own system of stratification of environments - and relief forms - based on a logic that can be explained, interpreted and articulated to the knowledge generated in the scientific means.
\end{abstract}

Keywords - landscape; ethno science; Cariri cearense

\footnotetext{
${ }^{1}$ Departamento de Geociências, URCA.
} 


\section{RESUMO}

O presente artigo objetiva discutir a geomorfologia semiárida nordestina a partir do conhecimento etnocientífico, visando compreender como os principais agentes modificadores do espaço do sertão entendem os processos geomórficos, como usam este conhecimento para o manejo do ambiente em que vivem e se, e como, utilizam estes saberes para algum tipo de taxonomia do relevo. Podemos concluir que os produtores rurais familiares do sertão tem vasto conhecimento sobre processos esculturadores do relevo, dominando um sistema próprio de estratificação dos ambientes - e das formas de relevo - com base em uma lógica que pode ser explicada, interpretada e articulada ao conhecimento gerado no meio científico.

Palavras-chave - paisagem; etnociência; cariri cearense.

\section{CONTEXTO DA PESQUISA}

Entendendo que a Ciência não deve fundar-se em verdades absolutas, e nem buscar respostas últimas, mas sim organizar, sistematizar e/ou produzir conhecimentos sobre as realidades percebidas pela sociedade, e afirmando que cada sociedade tem bases culturais e de percepção diferenciadas, parte do mundo acadêmico tem, nas últimas décadas, se voltado de forma mais interessada para os saberes produzidos por populações não inseridas na lógica moderna de produção do conhecimento, ou seja, aquelas comunidades que repassam vernacularmente o que aprenderam/aprendem de forma empírica em seu dia a dia de lida com a natureza. Sejam sobre indígenas, quilombolas, caiçaras, sertanejos, a análise científica do conhecimento tradicional tem sido uma referência importante para reavaliar os paradigmas dos modelos coloniais e agrícolas de desenvolvimento e servir de base à produção de novos modelos alternativos. 
Como afirma Ribeiro $(2012,2016)$, a realidade socioambiental das áreas semiáridas nordestinas apresenta, desde sua ocupação, uma desarticulação crônica entre o potencial e fragilidade ambientais, e as técnicas utilizadas para a produção. Baseadas em experiências exógenas, a maioria dos projetos de desenvolvimento realizados na região não produzem efeitos realmente duradouros e muitos, pelo contrário, causam danos, por vezes irreversíveis ao ambiente.

Muitos destes casos poderiam ser ao menos minimizados se estes projetos levassem em conta os saberes sobre a dinâmica ambiental advindos de gerações de uso e manejo dos recursos naturais pelas populações tradicionais que habitam esta área, a qual se constata ser bem mais complexa quando a entendemos de forma dinâmica no tempo e no espaço, numa integração sistêmica dos elementos da paisagem. Porém, a falta de conhecimento sobre a realidade ambiental e cultural das regiões semiáridas favorece muitas vezes, a implantação de programas governamentais não viáveis para a região, servindo como estímulo à migração.

As áreas semiáridas, devido a suas características morfoesculturadoras, quais sejam, alto poder erosivo das chuvas, solos pouco coesos e com pouca espessura, e baixa proteção da cobertura vegetal esparsa, apresentam um equilíbrio extremamente frágil diante da dinâmica ambiental. Quando a vegetação natural é retirada, os processos morfogênicos deflagrados pelos elementos do clima - em especial a erosão - tendem a se acelerar (RIBEIRO, 2004; 2012). 
Associado ao fato do Nordeste brasileiro ser a área semiárida mais habitada do mundo e que estas populações se aglomeram cada vez mais nos núcleos urbanos devido às dificuldades de se manterem no meio rural, a compreensão dos mecanismos que agem na dinâmica geomorfológica destas regiões é de suma importância para o seu ordenamento territorial.

Neste contexto, o presente artigo objetiva discutir a geomorfologia semiárida nordestina a partir do conhecimento etnocientífico, ou seja, com enfoque de cunho geográfico-etnográfico, visando compreender como os produtores rurais do sertão, com cultura tradicional, entendem os processos geomórficos, como usam este conhecimento para o manejo do ambiente em que vivem (em especial os saberes sobre erosão de solos, movimentos gravitacionais de massa e assoreamento dos cursos hídricos, em relação aos cultivos de subsistência e à pecuária) e se, e como, utilizam estes saberes para algum tipo de taxonomia do relevo/paisagem.

Para isso, é apresentada uma abordagem metodológica, com base científica, de todo um conjunto de teorias e práticas relativas ao ambiente, oriundas de uma experimentação empírica, e que contribui para orientar a inserção e o desenvolvimento de pesquisas junto a estas comunidades. Esta proposição metodológica pode ser utilizada para subsidiar políticas públicas de planejamento e gestão ambientais, sob a ótica do desenvolvimento local, partindo do pressuposto de que as informações que as pessoas possuem sobre seu ambiente, e a maneira pela qual elas categorizam estas informações, vão influenciar seu comportamento e seu aprendizado em relação a ele. 


\section{A ETNOGEOMORFOLOGIA.}

A sistematização do conceito de Etnogeomorfologia deu-se a partir de sua contextualização dentro das Etnociências, em busca do conhecimento das populações tradicionais sobre os processos geomórficos. Para isto, foram utilizados referenciais voltados para o diálogo entre saberes acadêmico-científicos oriundos de toda uma evolução científica ocidental baseada na razão e no método, e aqueles vernaculares, produzidos a partir da experiência vivida de sua utilização nas demandas diárias de sobrevivência, sendo destacados os trabalhos de BarreraBassols e Zinck (2003), Diegues (1996), Morin (2008a e 2008b), Porto-Gonçalves (2005), Escobar (2005), Sauer (1998; 2007), Sokal e Bricmont (2001), Toledo e Barrera-Bassols (2009), e Tuan (1980; 1983). Sobre a geomorfologia e seus processos, foram especialmente trabalhados conceitos de Tricart $(1977 ; 1983)$ Tricart e Cailleux (1972), Bólos (1992), Sotchava (1975), e Bertrand e Bertrand (2009a; 2009b).

Assim, surge o conceito de Etnogeomorfologia, como uma vertente da Geomorfologia que busca identificar e sistematizar os conhecimentos sobre formas e processos do relevo que comunidades de cultura tradicional produziram ao longo de gerações e hoje ainda são utilizados no modo como organizam seu espaço produtivo - especialmente o agropastoril.

Para tanto, Ribeiro (2012) indica que a Etnogeomorfologia deve focar no desvendamento das seguintes questões básicas: 1) como as comunidades tradicionais compreendem e utilizam as formas de relevo? 2) como reconhecem, 
nomeiam e classificam estas formas e seus processos esculturadores? e 3) de que maneira este conhecimento tradicional é utilizado na escolha dos usos e do manejo do solo?

E, para seu estudo, necessários se fazem conhecimentos de várias naturezas, como o geomorfológico, o geográfico, o pedológico e etnopedológico, o ecológico e etnoecológico, e o antropológico, voltando-se a etnogeomorfologia principalmente para a gestão e planejamento do uso do espaço.

\section{A ÁREA ESTUDADA - O CARIRI CEARENSE}

O espaço escolhido para o inicio dos estudos de etnogeomorfologia sertaneja - e locus das pesquisas da tese de doutorado relacionada - foi o Cariri cearense, composto por duas áreas geoambientalmente distintas e representativas da maior parte do Sertão nordestino - seu core, sedimentar, com grande aporte de recursos hídricos, solos mais férteis e uma densa aglomeração urbana (Crato-Juazeiro do Norte-Barbalha); e sua periferia cristalina, seca, com baixíssimos índices de produção.

Inicialmente focado apenas na sub-bacia do rio Salgado, na tese de RIBEIRO (2012), foram pesquisados os seguintes municípios/distritos, sendo entrevistadas populações em nove comunidades tradicionais (Quadro 1). 


\begin{tabular}{l|l|}
\hline Municípios/Distritos & Comunidades/Sitios \\
\hline Crato/Ponta da Serra & Sitio Catingueira \\
\hline Barbalha/Arajara & Sítios Farias e Sto. Antônio \\
\hline Mauriti/Palestina do Cariri & Sítios Cipó e Canabravinha \\
\hline Aurora/sede & Sítios Recreio, Tarrafas, Fazenda Velha e Barro Vermelho
\end{tabular}

Quadro 1: Locais pesquisados no projeto piloto (tese de doutorado) sobre Etnogeomorfologia Sertaneja (Ribeiro, 2012).

Atualmente vem sendo estudadas outras localidades do Cariri cearense, porém, não estando, ainda, seus resultados sistematizados. Neste artigo, são apresentadas as discussões sobre as comunidades inicialmente pesquisadas.

\section{UMA METODOLOGIA EM CONSTRUÇÃO}

Para o desvendamento e sistematização dos etnoconhecimentos geomórficos dos produtores rurais sertanejos, alguns procedimentos foram desenvolvidos, a partir das primeiras observações e conversas com estes atores sociais. E, como toda pesquisa que foca em elementos não essencialmente quantificáveis, como o é a cultura de um povo, estes procedimentos serviram apenas como uma linha mestra a ser repensada a cada ida ao campo, a fim de melhor captar a essência das conversas. Alguns itens, porém são essenciais:

Selecionar sertanejos com bastante experiência no trato com a terra e que mantem com o lugar de produção e moradia estreitos laços de afinidade, os quais 
repercutem diretamente no conhecimento de suas características e o uso desse saber no uso e manejo do solo.

Utilizar o método Bola-de-Neve para as entrevistas semiestruturadas, a partir de um roteiro prévio, buscando responder às seguintes questões: Qual a percepção ambiental geral sobre sua área de produção, ou seja, como eles veem o ambiente onde produzem? Se distinguirem formas de relevo, baseiam-se em que? Como as classificam/denominam? Compreendem os processos erosivos? Como? Fazem distinção entre estes processos? Baseados em que fazem esta distinção? Fazem alguma classificação? Relacionam estes processos a algum tipo de atividade humana? Utilizam este etnoconhecimento no uso e manejo dos solos das áreas produtivas? De que forma? De onde vêm estes conhecimentos?

Durante as entrevistas, visitaram-se as áreas produtivas para melhor observação do manejo do solo, assim como para identificação de cicatrizes de erosões e/ou movimentos gravitacionais de massa. Foram utilizadas, também, imagens fotográficas de cicatrizes para possível identificação destas como formas presentes em algum ponto da propriedade e/ou do sítio, e quando reconhecidas, feita toda uma tentativa de identificação de causa, consequências e nomenclaturas.

A partir dos dados coletados mediante as respostas dadas, organizou-se um quadro e, no qual procurou-se relacionar o etnoconhecimento com os saberes acadêmicos. 


\section{A ETNOGEOMORFOLOGIA COMO BASE PARA UM DIÁLOGO}

Os conhecimentos etnogeomorfológicos identificados entre os produtores rurais sertanejos de cultura de subsistência na sub-bacia do rio Salgado mostraram-se idênticos tanto em relação aos conceitos sobre fertilidade, erosão, movimentos gravitacionais de massa e sedimentação quanto às denominações e tipos de classificação das formas de relevo.

Sobre os conceitos sobre a dinâmica geomorfológica exógena - processos morfoesculturadores - desenvolvida pelos produtores rurais, existem alguns que se mostraram recorrentes e que são bem compreendidos por todos (RIBEIRO, 2012; 2013):

1 - o solo pode ser perdido através de dois processos: a erosão difusa, e a erosão concentrada. A erosão difusa que eles denominam "perda da goma da terra", é relacionada por eles principalmente a grandes quantidades de chuvas ("inverno muito forte"), mas também ao fato dos solos estarem "cansados". Segundo eles, quando não se devolve ao solo o que os cultivos retiram, os solos vão enfraquecendo e as chuvas fortes retiram a "goma da terra", ou seja, o que dava união às partículas dos solos (argilas e matéria orgânica), assim como a "vitamina da terra" (nutrientes), o que dá força ao plantio, indo, ambas, para os locais mais baixos do terreno ou para os rios e riachos, mesmo que não seja visível (sem cicatrizes). A erosão concentrada, que deixa cicatrizes nos terrenos ("solo cortado", "valetas" e "levadas"), também é vista como decorrência das chuvas fortes, porém, relacionadas principalmente (mas não somente) ao solo descoberto 
e ao uso de tratores, uma vez que o arado muito profundo traça os caminhos preferenciais para o escoamento das águas e acaba sendo "cavado" cada vez mais por elas.

2 - locais mais declivosos são mais propícios para processos de perda de solos tanto erosão quanto movimentos gravitacionais de massas, uma vez que os desníveis aumentam a força das águas.

3 - os movimentos gravitacionais de massa ocorrem devido ao encharcamento e consequente aumento de peso dos solos localizados em áreas de maiores declividades: segundo os entrevistados - principalmente aqueles dos sítios localizados em áreas próximas de serras ou da chapada do Araripe - quando há uma chuva muito intensa, o solo das áreas de "serras" ou do "talhado" (ou seja, com maiores declividades) absorve muita água, tornando-se mais pesados e acabam "desabando".

4 - se há perda de solos em um local, há acúmulo em outro: o solo perdido pelos processos erosivos vão se acumular em algum lugar mais baixo - nos "baixios" ou nos leitos dos rios e riachos. Assim, foram identificados locais onde os "baixios cresceram" (acumularam sedimentos e expandiram suas áreas), assim como, onde os "rios ficaram mais rasos" (assorearam).

5 - a fertilidade não é a única característica que deve ser considerada para classificar um solo como bom ou ruim: a "estrutura" (as características físicas) 
também é importante, uma vez que não adianta um solo ser fértil (ou seja, ter muitos nutrientes disponíveis), se apresentar muita pedregosidade ou ser muito duro. Segundo os entrevistados, os solos das "serras", geralmente são férteis, mas tem uma "estrutura" muito ruim para trabalhar (rasos e com muitas pedras misturadas), o que faz com que não sejam produtivos. Solos muito encharcados ("embrejados"), ou muito duros quando secos (aqueles que contêm argilas do tipo montmorilonitas em sua composição), podem apresentar também produtividades baixas pelas dificuldades em serem trabalhados.

Apesar de haver diferenças no tocante principalmente às formas de relevo - pois os locais de aplicação das entrevistas foram escolhidos exatamente buscando essas diferenças na morfologia - as classificações e nomenclaturas utilizadas pelos entrevistados se mostraram bastante similares. Em geral, foram identificadas quatro formas de relevo básicas: "serra", "pé-de-serra", "tabuleiros" e "baixios". Nas áreas mais próximas da Chapada do Araripe, outras formas de relevo foram identificadas: a "chapada" e o "talhado"; enquanto nas áreas pediplanadas do médio curso da sub-bacia do Salgado, duas outras formas de relevo foram identificadas, relacionadas com processos morfoesculturadores mais severos: os "serrotes" e as "areias" (Quadro 2).

Deste modo, podemos fazer uma relativa comparação entre a classificação do relevo feita a partir do conhecimento geomorfológico acadêmico, e aquela baseada na etnogeomorfologia sertaneja, oferendo um quadro correlativo entre 
estas duas formas de saber complementares quando se trabalha com desenvolvimento local (Quadro 3).

\begin{tabular}{|c|c|c|}
\hline $\begin{array}{l}\text { Unidade } \\
\text { etnogeomorfológica }\end{array}$ & \multicolumn{2}{|c|}{ Caracterização / descrição } \\
\hline CHAPADA & \multicolumn{2}{|c|}{$\begin{array}{l}\text { relevo mais elevado de toda a região, sua superfície de cimeira, com forma plana e } \\
\text { solos profundos, onde os processos morfoesculturadores são mínimos, não } \\
\text { havendo entalhamento significativo }\end{array}$} \\
\hline TALHADO & \multicolumn{2}{|c|}{$\begin{array}{l}\text { escarpa arenítica, com altíssima declividade (próxima a } 90 \text { graus), decorrente dos } \\
\text { processos evolutivos de recuo das escarpas da referida chapada, e que produz o } \\
\text { material que compóe os colúvios dos "pés-de-serra" e dos "baixios" }\end{array}$} \\
\hline SERRA & \multicolumn{2}{|c|}{$\begin{array}{l}\text { relevos mais altos e declivosos, onde os solos são mais rasos e pedregosos e os } \\
\text { principais processos morfoesculturadores são de degradação - erosões e } \\
\text { movimentos gravitacionais de massa }\end{array}$} \\
\hline PÉ-DE-SERRA & \multirow{2}{*}{$\begin{array}{l}\text { declividades medianas, verdadeiras } \\
\text { superfíries de transporte (e algumas } \\
\text { vezes de acumulação, quando a } \\
\text { declividade decai }\end{array}$} & $\begin{array}{l}\text { localizam-se junto às maiores elevações, } \\
\text { sendo pedimentos compostos basicamente } \\
\text { de colúvios mal sclecionados }\end{array}$ \\
\hline TABULEIROS & & $\begin{array}{l}\text { colinas rebaixadas pelos processos de } \\
\text { pediplanação, apresentando declividades } \\
\text { ainda mais baixas c solos mais rasos e } \\
\text { menos pedregosos que os primeiros }\end{array}$ \\
\hline SERROTE & \multirow{2}{*}{$\begin{array}{l}\text { colinas relacionadas com processos } \\
\text { morfoesculturadores mais severos - } \\
\text { representantes de fases do processo } \\
\text { de pediplanaçâo }\end{array}$} & $\begin{array}{l}\text { desníveis maiores compostas de solos } \\
\text { pedregosos }\end{array}$ \\
\hline AREIAS & & $\begin{array}{l}\text { muito rebaixadas e com solos mais } \\
\text { arenosos. }\end{array}$ \\
\hline BAIXIOS & \multicolumn{2}{|c|}{$\begin{array}{l}\text { terrenos mais baixos da paisagem, planos, com solos mais profundos originados } \\
\text { da acumulação de sedimentos trazidos das partes mais elevadas adjacentes }\end{array}$} \\
\hline
\end{tabular}

Quadro 2: As unidades etnogeomorfológicas identificadas pelos produtores sertanejos do Cariri cearense e seus significados acadêmicos, segundo Ribeiro (2012). 


\begin{tabular}{|c|c|c|}
\hline $\begin{array}{c}\text { Classificação do Relevo baseada } \\
\text { na Geomorfologia }\end{array}$ & Altimetria & $\begin{array}{l}\text { Classificação do relevo baseada na } \\
\text { Etnogeomorfologia Sertaneja }\end{array}$ \\
\hline Cimeira do Araripe & \multirow{5}{*}{ ط } & Chapada \\
\hline Encosta do Araripe & & $\begin{array}{c}\text { Talhado } \\
\text { Pé-de-serra }\end{array}$ \\
\hline Maciços e cristas residuais & & Serras \\
\hline Pedimento dissecado em colinas & & $\begin{array}{l}\text { Serrotes } \\
\text { Tabuleiros }\end{array}$ \\
\hline $\begin{array}{l}\text { Pediplano dissecado em colinas } \\
\text { rebaixadas }\end{array}$ & & $\begin{array}{c}\text { Serrotes } \\
\text { Tabuleiros } \\
\text { Areias }\end{array}$ \\
\hline Planícies e terraços fluviais & $\sqsupset$ & Baixios \\
\hline
\end{tabular}

Quadro 3: Correlação entre a classificação geomorfológica e a etnogeomorfológica no Cariri cearense (RIBEIRO, 2012).

Como observa Ribeiro (2012, p. 236):

"os etnoconhecimentos geomórficos (etnogeomorfologia) destes produtores rurais, foram desenvolvidos a partir de observações dos processos durante gerações ('empiricismo prático'), podemos considera-los como muito aproximados daqueles acadêmicos, distinguindo-se deles apenas pelas denominações dadas (às formas e processos) e ao componente eminentemente prático de seus conceitos, uma vez que foram produzidos de forma concomitante às necessidades de melhor compreender o ambiente do qual dependem para a sobrevivência".

\section{CONCLUSÕES}

De uma forma geral, a etnogeomorfologia sertaneja identifica e cria taxonomia àqueles processos e formas de relevo que tem influência mais direta sobre sua vida cotidiana. Por isso são classificadas duas formas básicas de relevo, baseadas na altimetria e nas declividades: as áreas altas e as áreas baixas. 
A primeira é relacionada às encostas, com declividades mais acentuadas e solos mais rasos, com mais pedregosidade, onde o uso e o manejo procuram ser menos intensivos devido á ocorrência mais constante de processos de perda de material erosões e movimentos gravitacionais de massa - processos compreendidos e classificados por eles.

As áreas baixas, em senso lato, referem-se ás áreas rebaixadas e planas da paisagem, onde a umidade é mais constante, os solos apresentam maior profundidade e podem ser feitos usos e manejos menos restritivos que nas áreas altas, uma vez que os processos morfoesculturadores mais comuns são os de deposição de sedimentos, o qual é composto por material mais fino e rico em nutrientes, advindo das áreas altas.

Dentro desta classificação geral, há uma setorização da paisagem: 1- as áreas altas subdividem-se em chapada, talhado, pé-de-serra, serra e serrotes, individualizadas principalmente em relação às declividades e aos tipos de solos que apresentam; 2as áreas baixas subdividem-se em tabuleiros, areias e baixios, diferenciadas principalmente segundo o tipo de solo (arenoso ou argiloso) e o aporte de umidade, sendo os baixios também identificados pela quase ausência de declividades.

Neste cruzamento de informações, podemos observar que as classificações etnogeomorfológicas apresentam correlação bastante alta com a classificação acadêmica (quando são levados em consideração os elementos altimetria, 
declividades e textura topográfica da paisagem, como feito na elaboração da compartimentação geomorfológica nesta tese), apesar da etnogeomorfologia sertaneja apresentar um maior detalhamento de compartimentos geomórficos. Isto se deve a dois fatores:

1) À escala de observação dos fatos, uma vez que a classificação acadêmica utilizada foi desenvolvida de forma regional, através de imagens SRTM na escala 1:400.000, enquanto a etnogeomorfológica é fruto de conhecimento utilitário cotidiano da paisagem, o que a deixa em uma escala do real, além do que, as nomenclatura utilizadas para designar os compartimentos geomórficos a classificação acadêmica muitas vezes deixa implícita a existência de variabilidade de formas;

2) À taxonomia etnogeomorfológica algumas vezes se repetir em compartimentações geomórficas acadêmicas diferentes, visto que não leva em consideração a gênese das formas e sim, apenas sua fisionomia e características pedológicas (como no caso dos serrotes e tabuleiros, identificados pelos entrevistados tanto nas áreas de pedimentos quanto nos pediplanos; estas formas apresentam-se como similares na etnogeomorfologia, porém, na classificação acadêmica, são manifestações de etapas diferenciadas do processo de aplainamento geral da região, onde as colinas do pediplano estão em um grau mais avançado de rebaixamento). 
Portanto, para fins de um desenvolvimento onde se procura uma maior articulação entre as potencialidades locais (recursos naturais, recursos humanos, cultura, infraestrutura, etc.), para organizar a produção com vistas a melhorias de vida da população, podemos propor a mesclagem dos conhecimentos acadêmicos e tradicionais, no tocante aos saberes etnogeomorfológicos, a fim de estimular as práticas benéficas à produção e ao ambiente, assim como, esclarecer de forma mais consistente, mais coerente, dentro da lógica cognitiva dos atores locais, o porquê de algumas formas de manejo do solo serem prejudiciais à manutenção de um ambiente saudável e de uma produção constante.

Assim, compreender o significado do relevo e seus processos formadores pelas comunidades tradicionais - uma verdadeira (re) construção da geomorfologia semiáridas à luz do conhecimento empírico e utilitário destes grupos sociais poderá levar à Geomorfologia acadêmica novas perspectivas de interpretação para a paisagem, a partir da utilização dos etno-modelos produzidos por estas culturas, os quais foram construídos historicamente a partir das observações e dos conhecimentos técnicos empregados no manejo de suas atividades de subsistência nas diferentes morfologias de seu território de ação ao longo do tempo.

Como já observava Aziz Ab'Saber em seu artigo "No domínio das caatingas" (2010, p.557-558):

"Os sertanejos têm pleno conhecimento das potencialidades produtivas de cada espaço ou subespaços dos sertões secos. Vinculado a uma cultura de longa maturação, cada grupo humano do Polígono das Secas tem sua própria espacialidade no pedaço em que trabalha." 


\section{REFERÊNCIAS BIBLIOGRÁFICAS}

AB'SABER, A.N. No domínio das caatingas. In MONDENESI-GAUTIERRI, M.C.; BARTORLLI, A.; MANTESSO-NETO, V.; CARNEIRO, C.D.R. e LISBOA, M.B.A.L. (org.) A obra de Aziz Nacib Ab’Saber. São Paulo: Beca-BALL edições, 2010. p. 553560.

BARRERA-BASSOLS, N. e ZINCK, J.A. Ethnopedology: a worldwide view on the soil knowledge of local people. Geoderma, Londres: Elsivier, n. 111, 2003, p. 171-195.

BERTRAND, C. e BERTRAND, G. O Geossistema: um espaço-tempo antropizado esboço de uma temporalidade ambiental. In: BERTRAND, C. e BERTRAND, G. Uma geografia transversal e de travessias - o meio ambiente através dos territórios e das temporalidades. Maringá/PR: Massoni, 2009a, p. 307-314.

BERTRAND, G. E BERTRAND, C. O sistema GTP (Geossistema, Territótio, Paisagem). O retorno do geográfico? In: BERTRAND, C. e BERTRAND, G. Uma geografia transversal e de travessias - o meio ambiente através dos territórios e das temporalidades. Maringá/PR: Massoni, 2009b, p. 305-306.

BÓLOS, M. (org.) Manual de ciencia del paisaje - teoría, métodos y aplicaciones. Barcelona: Masson, 1992. 273 p.

DIEGUES, A.C. S. O mito moderno da natureza intocada. São Paulo: HUCITEC, 1996. $169 p$.

ESCOBAR, A. O lugar da natureza e a natureza do lugar: globalização ou pósdesenvolvimento? In: LANDER ,E. (org) A colonialidade do saber: eurocentrismo e ciências sociais. Perspectivas latino-americanas. Ciudad Autônoma de Buenos Aires/AR: CLACSO (Colección Sur Sur) 2005, p. 133-168. Disponível em http://bibliotecavirtual.clacso.org.ar/ar/libros/lander/pt/Escobar.rtf. Acesso em 10.jul.2009.

MORIN, E. Ciência com consciência. 11.ed. rev e mod. Rio de Janeiro: Bertrand Brasil, 2008a. 350 p.

MORIN, E. O método 1 - a natureza da natureza. 2.ed. Porto Alegre: Sulina, 2008b. 479 p. 
PORTO-GONÇALVES, C.W. Apresentação da edição em português. In: LANDER, E.(org) A colonialidade do saber: eurocentrismo e ciências sociais. Perspectivas latinoamericanas. Ciudad Autônoma de Buenos Aires/AR: CLACSO (Colección Sur Sur) 2005, p. 9-15. $\quad$ Disponível em http://bibliotecavirtual.clacso.org.ar/ar/libros/lander/pt/ApreemPort.rtf. Acesso em 10.jul.2009

RIBEIRO, S.C. Etnogeomorfologia na Perspectiva da Gestão Ambiental e Aprendizagem na Educação Básica. Espaço Aberto, PPGG - UFRJ, V. 6, N.1, p. 175-190, 2016.

RIBEIRO, S.C. Etnogeomorfologia sertaneja: proposta metodológica para a classificação das paisagens da sub-bacia do rio Salgado/CE. Rio de Janeiro: UFRJ/PPGG, 2012. (tese de doutorado).

RIBEIRO, S.C. Susceptibilidade aos Processos Erosivos Superficiais com Base na Dinâmica Geomorfológica na Microbacia do Rio Grangeiro, Crato/CE. Rio de Janeiro: UFRJ/PPGG, 2004.148 p. (Dissertação de Mestrado).

RIBEIRO, S.C.; MARÇAL, M.S.; CORREA, A.C.B. e LIMA, G.G. Etnogeomorfologia sertaneja - o conhecimento tradicional do produtor rural nordestino sobre o relevo e seus processos na sub-bacia do rio Salgado/CE. X ENANPEGE - Geografias, Políticas Públicas e Dinâmicas Territoriais, Campinas/SP: 07 a 10 de outubro de 2013. Anais... Campinas: ANPEGE: 2013. P. 3166-3177.

SAUER, C.O. A morfologia da paisagem. In: CORRÊA, R.L. e ROZENDAHL, Z. (Orgs.). Paisagem tempo e cultura. Rio de Janeiro: EdUERJ, 1998.

SAUER, C.O. Geografia cultural. In: CORREA, R.L. e ROSENDAHL, Z. Introdução à geografia cultural. Rio de Janeiro: Bertrand Brasil, 2007. P. 19-26.

SOKAL, A. e BRICMONT, J. 2.ed. Imposturas intelectuais - o abuso da ciência pelos filósofos pós-modernos. Rio de Janeiro: Record, 2001.

SOTCHAVA, V. O estudo dos geossistemas. Métodos em questão. São Paulo: IGUSP, 1975.

TOLEDO, V. M. e BARRERA-BASSOLS, N. A etnoecologia: uma ciência pós-normal que estuda as sabedorias tradicionais. Desenvolvimento e Meio Ambiente, n. 20, p. 31 45, jul./dez. 2009. 
TRICART, J e CAILLEUX, A. Introduction to climatic geomorphology. Londres: Longman group limited, 1972. 295p.

TRICART, J. As zonas morfoclimáticas do Nordeste brasileiro. ROSADO, V. (sel. e org.) Sétimo livro das secas. Mossoró/RN: Escola Superior de Agricultura de Mossoró/Fundação Guimarães Duque, 1983. p. 53-63.(Coleção Mossoroense, v. 210)

TRICART, J. Ecodinâmica. Rio de Janeiro: FIBGE, 1977.

TUAN, Y. Topofilia - um estudo da percepção, atitudes e valores do meio ambiente. São Paulo: DIFEL, 1980.

TUAN, Y-F. Espaço e Lugar: A perspectiva da Experiência. Tradução de Lívia de Oliveira, São Paulo: DIFEL, 1983. 